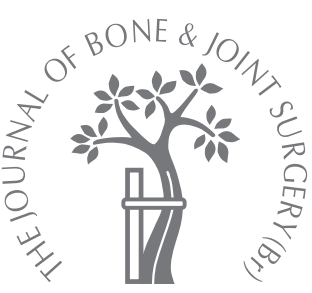

S. Agarwala,

S. Shah,

V. R. Joshi

From the P. D.

Hinduja National

Hospital and Medical

Research Centre,

Mumbai, India

\title{
The use of alendronate in the treatment of avascular necrosis of the femoral head
}

\author{
FOLLOW-UP TO EIGHT YEARS
}

- S. Agarwala, MS(Orth), $\mathrm{MCh}$ (Orth), Chief of Surgery, Head of Orthopedics and Traumatology

In. Shah, MS(Orth), Associate Consultant Orthopaedic Surgeon

V. R. Joshi, MD, FRCP, Consultant Physician and Rheumatologist

P. D. Hinduja National Hospital and Medical Research Centre, Mahim, Mumbai 400016, India.

Correspondence should be sent to Dr S. Agarwala; e-mail: drsa@rediff.com

(C)2009 British Editorial Society of Bone and Joint Surgery doi:10.1302/0301-620X.91B8. $21518 \$ 2.00$

$J$ Bone Joint Surg $[\mathrm{Br}]$ 2009;91-B:1013-18.

Received 8 July 2008; Accepted

after revision 25 March 2009

\begin{abstract}
The use of bisphosphonates in the treatment of avascular necrosis of the femoral head is an encouraging but relatively new option with most published data being derived from small trials with limited follow-up. We present a clinicoradiological analysis of 395 hips with avascular necrosis which were treated with oral alendronate for three years with a mean follow-up of four years (1 to 8).

Our results show an improvement in the clinical function, a reduction in the rate of collapse and a decrease in the requirement for total hip replacement, compared with the findings of other studies in which no treatment was given. This improvement is particularly marked if the treatment is begun in the pre-collapse stages of the disease. Even in Ficat stage-III hips some benefit was obtained from treatment with alendronate by at least a delay in the need for total hip replacement.
\end{abstract}

Osteonecrosis or avascular necrosis of the femoral head can cause structural failure of bone with collapse and dysfunction of the hip. ${ }^{1} \mathrm{Col}-$ lapse of the femoral head was observed in $75 \%$ of cases of avascular necrosis of the femoral head within three years of presentation by Merle d'Aubigné et $\mathrm{al}^{2}$ and in $80 \%$ within four years of onset of hip pain due to avascular necrosis by Ohzono et al. ${ }^{3}$ According to Aaron et al, ${ }^{4}$ more than $50 \%$ of patients with avascular necrosis of the femoral head require THR within three years of diagnosis. Indeed, it is reported to be the most common cause of THR in young adults. ${ }^{5}$

Agarwala et $\mathrm{al}^{6}$ first reported the efficacy of alendronate, a bisphosphonate, in the treatment of avascular necrosis of the femoral head and showed that it not only improved the symptoms but also retarded progression of the disease and reduced the rate of collapse of the femoral head. ${ }^{7,8}$ Other studies have shown similar results ${ }^{9,10}$ and bisphosphonates are now considered to be one of the standard options of treatment for avascular necrosis of the femoral head. ${ }^{11}$

We have offered alendronate as the primary line of management to all of our patients with avascular necrosis of the femoral head. We have analysed the outcome in 294 patients (395 hips) with avascular necrosis of the femoral head treated with alendronate over a period of eight years and compared our findings with known data regarding the natural history of avascular necrosis of the femoral head.

\section{Patients and Methods}

Between 1999 and 2006, we saw 434 patients with avascular necrosis of the femoral head. Of these, 48 were excluded because they already had degenerative arthritis (Ficat and Arlet stage IV $^{12}$ ) and a further 63 who had concurrent peptic ulceration or hepatorenal derangement. Thus, 323 patients received alendronate, of whom ten were lost to follow-up in less than one year of starting alendronate therapy and 19 opted for surgery before completion of one year of treatment. This latter group was considered to be early failures. A minimum followup of one year was an inclusion criterion and 294 patients (395 hips) were included in the study. The mean age at presentation was 39.1 years ( 22 to 55 ) with 202 male and 92 female patients. The mean follow-up was four years (1 to 8 ) (Table I).

All the patients received $10 \mathrm{mg}$ of alendronate per day with standard precautions for a period of three years along with a daily oral supplement of $500 \mathrm{mg}$ to $1000 \mathrm{mg}$ of calcium and of $400 \mathrm{IU}$ to $800 \mathrm{IU}$ of vitamin $\mathrm{D}_{3}$. For control of pain, analgesics and non-steroidal antiinflammatory agents were given as needed. In the first three months of treatment, all the patients were advised to use toe-touch weightbearing when walking using elbow or axillary crutches with weight-bearing increased gradually as dictated by pain.

After the first visit, the patients were followed up every three months for the first year and 
Table I. Duration of symptoms before starting treatment and of follow-up of hips for each Ficat and Arlet stage

\begin{tabular}{|c|c|c|c|}
\hline & $\begin{array}{l}\text { Number of } \\
\text { hips }\end{array}$ & $\begin{array}{l}\text { Mean (SD, range) duration of hip pain } \\
\text { (mths) before treatment }\end{array}$ & $\begin{array}{l}\text { Mean (SD, range) follow-up } \\
\text { (yrs) }\end{array}$ \\
\hline \multicolumn{4}{|c|}{ Ficat and Arlet stage at the commencement of treatment } \\
\hline 1 & 215 & $7.8(4.9,1$ to 36$)$ & $4.0(2.2,1$ to 8$)$ \\
\hline II & 129 & $14.7(11.0,2$ to 48$) 10.4(8.4,1$ to 48$)$ & $4.3(2.1,1$ to 8$)$ \\
\hline III & 51 & $25.8(15.8,6$ to 60$)$ & $3.7(2.1,1$ to 8$)$ \\
\hline Total & 395 & $12.4(11.0,1$ to 60$)$ & $4.0(2.2,1$ to 8$)$ \\
\hline
\end{tabular}

annually thereafter and also if their pain increased suddenly. The annual visits were continued even after cessation of alendronate treatment at three years. The lack of an indigenous hip functional scoring system and poor compatibility of the existing scores with the activities of daily living of Indian patients, required us to record pain and function using simple parameters. At presentation and at each follow-up visit, pain and disability scores were recorded on a verbal response scale of 0 to 10 ( 0 for no pain, 10 for the most severe) while time for which continuous standing could be tolerated during activities of daily living and maximum uninterrupted walking time were recorded in minutes. The duration of hip pain before starting treatment was recorded while at follow-up visits, the consumption of analgesics and the side-effects of the drug, if any, were also noted. All the data recorded were compared with the corresponding parameters at previous visits and discussed with the patients to encourage adherence to this long-term daily treatment.

Plain anteroposterior (AP) pelvic radiographs were repeated at every visit. The Ficat and Arlet ${ }^{12}$ staging of the femoral head was reported by an independent blinded radiologist. The duration of symptoms at presentation and the results are shown in Table I. Financial constraints prevented MRI being performed in all the patients and it was reserved for patients with suspected Ficat stage-I avascular necrosis of the femoral head.

Patients were considered to be lost to follow-up if they did not attend for their annual visit up to six months after their appointment despite reminders by telephone. Some patients were lost to follow-up after a few regular annual visits and the clinicoradiological data recorded before this are included in the present analysis.

Clinical failure was defined as deterioration on the basis of pain/disability scores and standing or walking time, severe enough to require THR. The hips which did not fail were considered to be survived hips. Radiological progression was defined as worsening of the radiological appearance by one grade or more on the Ficat and Arlet scale and was considered to be a radiological failure. Radiological collapse was defined as progression of the Ficat stage I or II to Ficat stage III.

Post-treatment hips comprised the subgroup of patients who had been followed up for a minimum of one year (1 to 5) after having completed the three-year course of alendronate treatment. A comparison with the available historical data of clinical failure and radiological progression was undertaken in all the hips available including the post-treatment hip subgroup to evaluate any after-effect of the treatment.

Statistical analysis. The mean values of the pain, disability scores and standing and walking times at various time intervals were compared with those at presentation. The Wilcoxon signed-rank test was used as the test of significance between groups after confirming the normal distribution of the result using the Shapiro-Wilk test. Kaplan-Meier survival curves were plotted for the clinical survival of the groups and $95 \%$ confidence intervals $(\mathrm{CI})$ were calculated. The log rank test was used as test of significance.

A p-value $<0.05$ was deemed to be statistically significant. SPSS version 15.0 software (SPSS Inc., Chicago, Illinois) was used to analyse the data.

\section{Results}

The numbers of hips for which information on outcome was available for analysis at various periods of follow-up is presented in Table II while loss to follow-up and clinical failure are shown in Table III.

At a mean follow-up of four years (1 to 8), 364 hips $(92.2 \%)$ had a satisfactory clinical result and had not required any surgery. Failure requiring THR occurred in 4 of 215 (2\%) of Ficat stage-I hips, 10 of 129 (8\%) of Ficat stage-II and in 17 of $51(33 \%)$ of Ficat stage-III hips.

Kaplan-Meier survival analysis for the stages of avascular necrosis of the femoral head shown at presentation is given in Figure 1. Compared with Ficat stage-III hips, stage I- and stage-II hips showed a significantly higher probability of survival (log rank test, $\mathrm{p}<0.001$ for all associations).

The clinical outcome measures after treatment with alendronate are shown in Figure 2 and presented in Table IV. Other than in stage-III disease the mean scores remained significantly better than at presentation, long after discontinuation of treatment at three years.

The radiological progression is recorded in Table $\mathrm{V}$ and presented as a rate of collapse in Figure 3. At a mean follow-up of four years (1 to 8 ), the overall collapse rate was $28.8 \%$ (99 of 344 hips) in stage-I and stage-II hips taken together and $12.6 \%$ (27 of 215 ) in stage-I and $55.8 \%$ (72 of the 129) in stage-II hips. The mean time to collapse was 3.1 years ( 2 to 6 ) (3.5 years ( 3 to 6 ) for stage-I and 2.9 years ( 2 to 5 ) for stage-II hips). Radiological progres- 
Table II. Number of hips available for analysis over eight years

\begin{tabular}{lccccccccc}
\hline & \multicolumn{1}{l}{ Follow-up (yrs) } \\
\cline { 2 - 10 } Year of onset of treatment & $\mathbf{1}$ & $\mathbf{2}$ & $\mathbf{3}$ & $\mathbf{4}$ & $\mathbf{5}$ & $\mathbf{6}$ & $\mathbf{7}$ & $\mathbf{8}$ \\
\hline 1999 & 45 & 45 & 45 & 44 & 42 & 40 & 37 & 32 \\
2000 & 42 & 42 & 41 & 40 & 38 & 35 & 32 & -- \\
2001 & 50 & 50 & 49 & 48 & 46 & 44 & -- & -- \\
2002 & 39 & 39 & 38 & 37 & 35 & -- & -- & -- \\
2003 & 46 & 46 & 45 & 44 & -- & -- & -- & -- \\
2004 & 58 & 56 & 55 & -- & -- & -- & -- & -- \\
2005 & 65 & 63 & -- & -- & -- & -- & -- & -- \\
2006 & 50 & -- & -- & -- & -- & -- & -- & - \\
Number of hips analysed & 395 & 341 & 273 & 213 & 161 & 119 & 69 & 32 \\
\hline
\end{tabular}

Table III. Loss to follow-up and clinical failure at follow-up

\begin{tabular}{lllllllll}
\hline & \multicolumn{1}{l}{ Follow-up period (yrs) } \\
\cline { 2 - 9 } & $\mathbf{1}$ & $\mathbf{2}$ & $\mathbf{3}$ & $\mathbf{4}$ & $\mathbf{5}$ & $\mathbf{6}$ & $\mathbf{7}$ & $\mathbf{8}$ \\
\hline Loss to follow-up & 3 & 4 & 4 & 6 & 4 & 4 & 5 & $*$ \\
Clinical failure & 1 & 2 & 3 & 5 & 6 & 5 & 4 & 5 \\
\hline
\end{tabular}

* the six-month period after follow-up due at eight years not yet reached

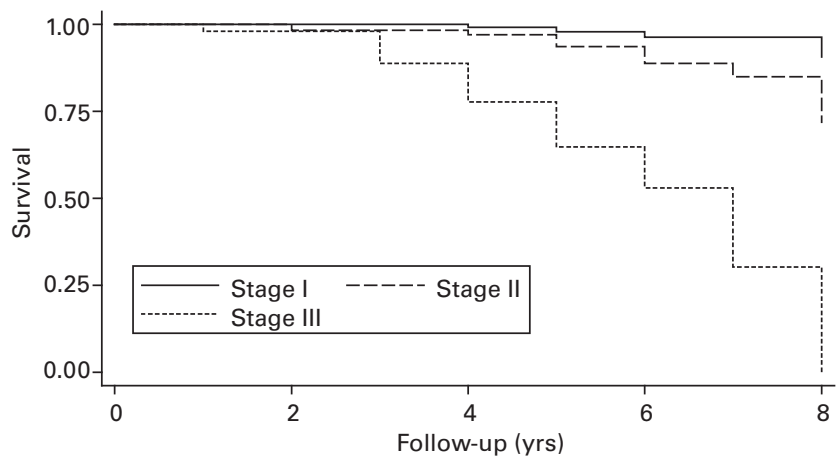

Fig. 1

Kaplan-Meier survival analysis showing hips with avascular necrosis of the femoral head grouped according to the Ficat and Arlet stage at onset of treatment.

sion was seen in 179 of 395 hips (45\%) that included 99 of $215(46 \%)$ hips in stage-I, 70 of $129(54 \%)$ of stage-II hips and 10 of $51(20 \%)$ of stage-III hips.

The analgesic requirement of all the patients who responded to alendronate (clinical survival) decreased gradually and the maximum duration was only two months after commencing treatment with alendronate. Mild dyspeptic symptoms were noticed in ten patients and headache and dizziness in six. These did not warrant the cessation of treatment and all resolved in less than a month. No other adverse effect was noted in any patient.

\section{Discussion}

A number of recent studies ${ }^{7,9,10,13}$ have successfully used bisphosphonates for the treatment of avascular necrosis of the femoral head on the premise that the anti-resorptive and anti-inflammatory actions of this drug ${ }^{1,14,15}$ will counter the structural bone weakening caused by reparative osteocytic necrosis and apoptosis. ${ }^{16,17}$ However, all these studies were based on a short-term follow-up, ${ }^{7,9,10,13}$ There is experimental evidence that alendronate increases bone mineral density. ${ }^{18}$

Earlier studies of the natural history of avascular necrosis of the femoral head ${ }^{2,19-21}$ have reported an overall clinical rate of progression of $77 \%$ to $98 \%$ and a radiological progression rate of $68 \%$ to $75 \%$ at a mean follow-up of three years. In a review of 21 studies involving 819 hips followed for a mean of 34 months, only $22 \%$ were found to have a satisfactory clinical result following non-operative treatment, defined as no further need of surgical intervention. ${ }^{5}$ Of the 559 hips with radiological follow-up, $74 \%$ progressed radiologically. By contrast, in our study of 395 hips with a mean follow-up of four years following alendronate treatment, a satisfactory clinical result, defined as no surgical intervention, was seen in $92 \%$ of hips while radiological progression was seen in 179 of 395 hips (45\%). Historical reports note a rate of collapse of the femoral head of $75 \%$ and $80 \%$ at two and four years, respectively, compared with our experience of $29 \%$ at four years. In untreated hips the conversion rate to THR was reported as $>50 \%$ at three years ${ }^{4}$ and $64 \%$ at two years. ${ }^{9}$ Recent studies have reported results according to the Ficat stage ${ }^{22}$ defining clinicoradiological failure as that used in our study. The proportions of hips requiring THR were $2 \%, 8 \%$ and $33 \%$ for stagedI, -II and -III disease respectively compared with $65 \%, 69 \%$ and $87 \%$ respectively as reported by Mont and Hungerford ${ }^{5}$ in untreated hips. Other reports categorising outcome according to the Ficat and Arlet grade at presen- 

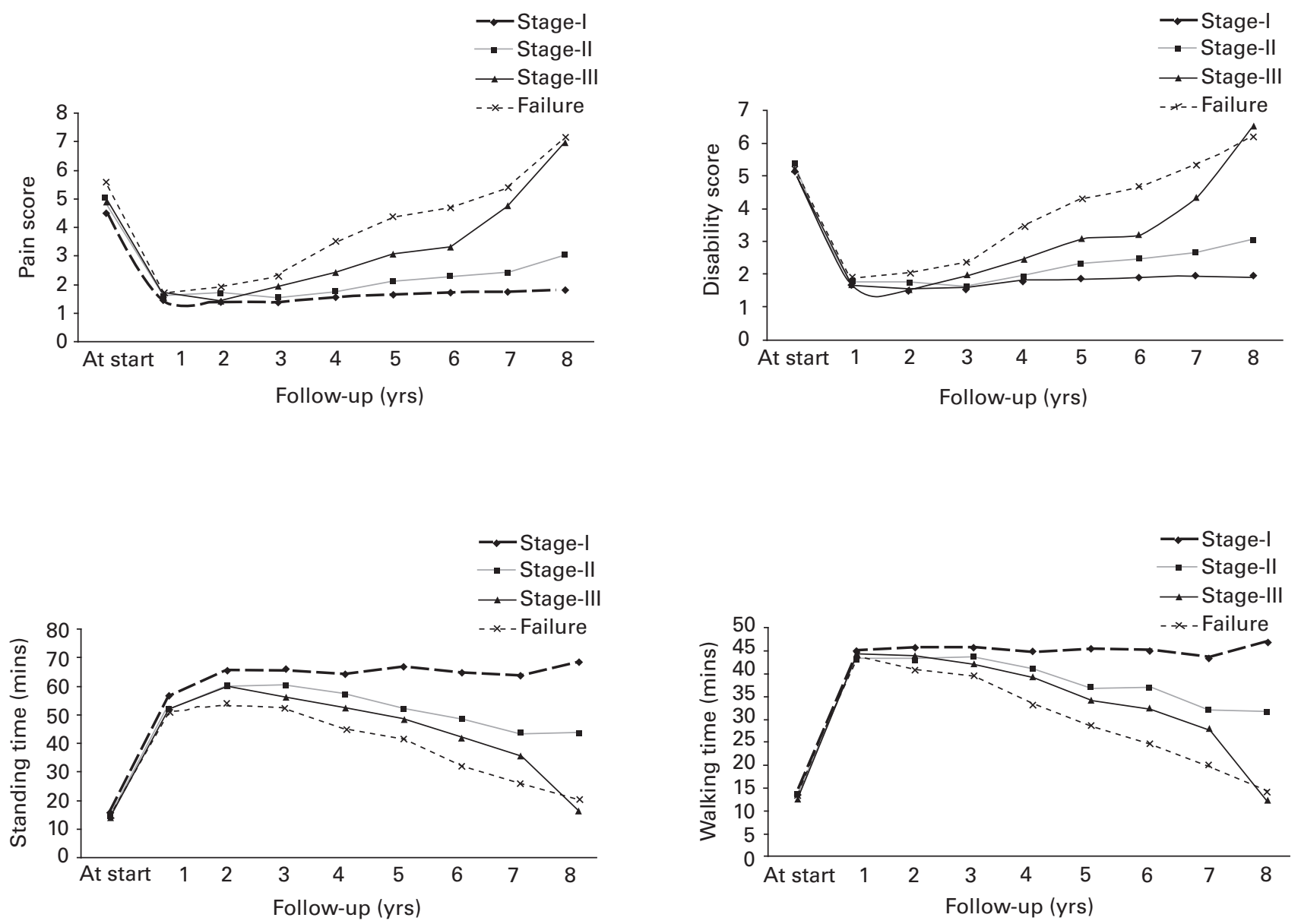

Fig. 2

Graphs showing the clinical outcome measures to a maximum of eight years after presentation. The results are separated into the avascular stages shown at the onset of treatment.

tation all describe worse results than we achieved in our patients who were treated with alendronate. ${ }^{23-28}$ This indicates a sustained action of alendronate in postponing surgical intervention and retarding the progression of collapse in all grades of avascular necrosis of the femoral head, but more marked in stage-I and stage-II disease. The length of followup of our study exceeded that of others ${ }^{23-28}$ allowing the conclusion to be drawn that alendronate given for three years maintains its benefits for up to eight years in some patients.

The natural history of untreated avascular necrosis of the femoral head based on MRI evaluation has recently been described. ${ }^{29-32}$ The MRI-based Steinberg classification of avascular necrosis of the femoral head includes stages 0 to 3 which correspond to the pre-collapse Ficat grades I and II. ${ }^{25}$ Survival rates ranging between $20 \%$ and $60 \%$ have been reported for Steinberg stage- 1 to stage- 3 hips at four to five years. ${ }^{27,28}$ Our experience at a mean duration of four years identified a combined rate of survival for Ficat stage-I and stage-II, of more than $90 \%$ (Fig. 1) confirming a favourable role of alendronate in earlier grades of avascular necrosis of the femoral head.
In the literature the general premise is that once collapse of the femoral head occurs, progression is relentless and that no conservative management is effective. ${ }^{5,28,33-38}$ Additionally, it has been reported that avascular necrosis as a diagnosis is a predisposing factor for early failure in THR or surface replacement. ${ }^{39-42}$ Any medical management of this disease which at least defers the requirement for THR among these young patients with grade-III disease would be worthwhile.

The duration of alendronate therapy still needs to be optimised. Our results have shown that from three years onwards, there is a rapid deterioration of hips which were already at stage-III at the time of commencement of treatment. This suggests that in this advanced stage the process may be better controlled if the drug is continued for a longer period of time.

Our study started in 1998 and was limited by lack of access to routine MRI or the more recent quantitative digital image analysis, ${ }^{43}$ which precluded the use of newer classification systems based on the site, size and progression of the lesion. ${ }^{44}$ However. considering the large number of hips studied and the follow-up for some extending to eight 
Table IV. Mean (SD) of clinical scores at various intervals (yrs) with statistical comparison with the score at presentation using the Wilcoxon signedrank test

\begin{tabular}{|c|c|c|c|c|c|c|c|c|c|c|c|c|c|}
\hline & \multirow[b]{2}{*}{ At onset } & \multicolumn{12}{|c|}{ Years } \\
\hline & & 1 & & & 3 (alendron & nate stopped) & 6 & & & 7 & & 8 & \\
\hline \multicolumn{14}{|l|}{ Stage-I } \\
\hline Pain score & $4.5(1.8)$ & 1.5 & $(0.9)$ & $\mathrm{p}<0.001$ & $1.4(0.9)$ & $\mathrm{p}<0.001$ & 1.8 & (1.3) & $p<0.001$ & $1.8(1.0)$ & $p<0.001$ & $1.8(1.8)$ & $\mathrm{p}<0.001$ \\
\hline Disability score & $5.1(1.4)$ & 1.7 & (1.0) & $\mathrm{p}<0.001$ & $1.5(0.9)$ & $p<0.001$ & 1.9 & (1.3) & $p<0.001$ & $1.9(1.1)$ & $\mathrm{p}<0.001$ & $1.9(1.6)$ & $\mathrm{p}<0.001$ \\
\hline Standing time & $16.3(7.0)$ & 59.2 & $(17.1)$ & $p<0.001$ & $68.9(24.3)$ & $\mathrm{p}<0.001$ & 67.5 & $(28.8)$ & $p<0.001$ & $66.4(25.3)$ & $p<0.001$ & 71.8 (28.7) & $p<0.001$ \\
\hline Walking time & $13.7(5.4)$ & 44.8 & $(13.1)$ & $p<0.001$ & 45.8 (15.3) & $p<0.001$ & 45.0 & $(16.5)$ & $p<0.001$ & $43.5(17.4)$ & $p<0.001$ & 46.8 (17.3) & $p<0.001$ \\
\hline \multicolumn{14}{|l|}{ Stage-II } \\
\hline Pain & $5.1(1.7)$ & 1.6 & $(0.3)$ & $\mathrm{p}<0.001$ & $1.6(0.9)$ & $\mathrm{p}<0.001$ & 2.3 & $(1.7)$ & $\mathrm{p}<0.001$ & $2.4(1.7)$ & $\mathrm{p}<0.001$ & $3.0(2.1)$ & $p=0.01$ \\
\hline Disability score & $5.3(1.5)$ & 1.8 & $(1.1)$ & $\mathrm{p}<0.001$ & $1.6(0.8)$ & $\mathrm{p}<0.001$ & 2.5 & $(1.5)$ & $\mathrm{p}<0.001$ & $2.6(1.7)$ & $\mathrm{p}<0.001$ & $3.0(1.7)$ & $p<0.001$ \\
\hline Standing time & $14.7(6.6)$ & 54.1 & $(14.1)$ & $p<0.001$ & $62.7(28.9)$ & $p<0.001$ & 50.6 & $(20.1)$ & $p<0.001$ & $45.9(25.0)$ & $p<0.001$ & $45.4(20.1)$ & $\mathrm{p}<0.001$ \\
\hline Walking time & $13.4(5.2)$ & 43.2 & $(13.3)$ & $p<0.001$ & $43.5(14.4)$ & $p<0.001$ & 36.8 & $(15.4)$ & $p<0.001$ & $32.2(17.8)$ & $\mathrm{p}<0.001$ & $31.5(18.0)$ & $p<0.001$ \\
\hline \multicolumn{14}{|l|}{ Stage-III } \\
\hline Pain score & $4.9(1.7)$ & 1.7 & $(1.2)$ & $\mathrm{p}<0.001$ & $2.0(2.0)$ & $p<0.001$ & 3.3 & $(2.0)$ & $\mathrm{p}<0.001$ & $4.8(2.2)$ & $p=0.34$ & $7.0(0.0) p$ & $p=0.32$ \\
\hline Disability score & $5.2(1.4)$ & 1.6 & $(1.1)$ & $\mathrm{p}<0.001$ & $1.9(1.7)$ & $p<0.001$ & 3.1 & $(2.1)$ & $p<0.001$ & $4.3(2.0)$ & $p=0.86$ & $6.5(0.7)$ & $p=0.18$ \\
\hline Standing time & $14.5(6.3)$ & 54.5 & $(11.6)$ & $\mathrm{p}<0.001$ & $58.4(23.1)$ & $p<0.001$ & 43.6 & $(20.6)$ & $\mathrm{p}<0.001$ & $37.1(21.6)$ & $p=0.04$ & $17.5(3.5) p$ & $p=1.00$ \\
\hline Walking time & $12.6(4.7)$ & 44.5 & $(12.1)$ & $\mathrm{p}<0.001$ & $42.0(16.5)$ & $\mathrm{p}<0.001$ & 32.2 & $(15.7)$ & $\mathrm{p}<0.001$ & $27.9(14.4)$ & $p=0.04$ & $12.5(3.5)$ & $p=0.32$ \\
\hline
\end{tabular}

Table V: The radiological status of the hips at follow-up

\begin{tabular}{|c|c|c|c|c|}
\hline \multirow[b]{2}{*}{ Follow-up duration (yrs) } & \multicolumn{4}{|c|}{ Stage } \\
\hline & I & II & III & IV \\
\hline \multicolumn{5}{|l|}{$1(n=395)$} \\
\hline At onset & 215 & 129 & 51 & 0 \\
\hline At last visit & 214 & 120 & 61 & 0 \\
\hline \multicolumn{5}{|l|}{$2(n=341)$} \\
\hline At onset & 179 & 117 & 45 & 0 \\
\hline At last visit & 120 & 149 & 72 & 0 \\
\hline \multicolumn{5}{|l|}{$3(n=274)$} \\
\hline At onset & 146 & 96 & 32 & 0 \\
\hline At last visit & 73 & 110 & 90 & 1 \\
\hline \multicolumn{5}{|l|}{$4(n=213)$} \\
\hline At onset & 112 & 77 & 24 & 0 \\
\hline At last visit & 51 & 76 & 75 & 11 \\
\hline \multicolumn{5}{|l|}{$5(n=161$} \\
\hline At onset & 85 & 58 & 18 & 0 \\
\hline At last visit & 38 & 48 & 63 & 12 \\
\hline \multicolumn{5}{|l|}{$6(n=109)$} \\
\hline At onset & 59 & 39 & 11 & 0 \\
\hline At last visit & 24 & 34 & 41 & 10 \\
\hline \multicolumn{5}{|l|}{$7(n=69)$} \\
\hline At onset & 39 & 23 & 7 & 0 \\
\hline At last visit & 13 & 26 & 21 & 9 \\
\hline \multicolumn{5}{|l|}{$8(n=32)$} \\
\hline At onset & 17 & 13 & 2 & 0 \\
\hline At last visit & 4 & 14 & 9 & 5 \\
\hline
\end{tabular}

years, the information obtained suggests that the natural history of avascular necrosis of the femoral head can be favourably altered by alendronate.

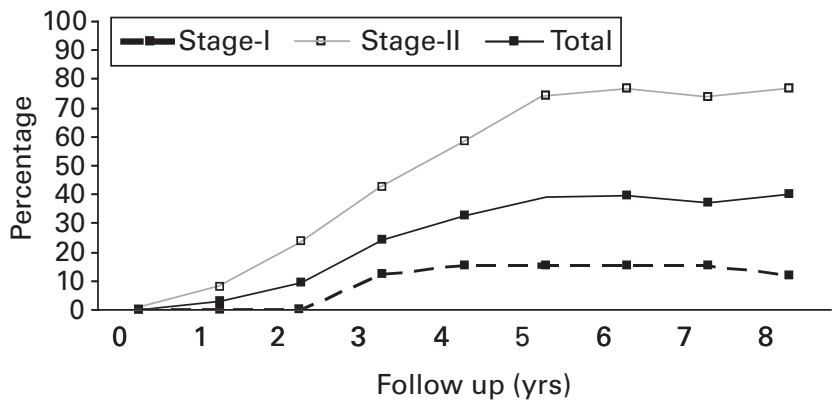

Fig. 3

Graph showing the percentage of collapsed hips over follow-up for eight years.

We thank Dr R. Mankeshwar for the statistical analysis and Dr B. U. Pai, Consultant Radiologist at P. D. Hinduja National Hospital and Medical Research Centre for radiological input.

No benefits in any form have been received or will be received from a commercial party related directly or indirectly to the subject of this article.

\section{Supplementary material}

$\because$ A further opinion showing a comparison of clinical e and radiological fracture rates in treatment of avascular necrosis of the femoral head as seen in previous studies with those in our present study is available with the electronic version of this article on our website at www.jbjs.org.uk

\section{References}

1. Astrand J, Aspenberg P. Systemic alendronate prevents resorption of necrotic bone during revascularisation: a bone chamber study in rats. BMC Musculoskeletal Disord 2002;3:19.

2. Merle d'Aubigné R, Postel M, Mazabraud A, Massias P, Guegen J. Idiopathic necrosis of the femoral head in adults. J Bone Joint Surg [Br] 1965;47-B:612-33. 
3. Ohzono K, Saito M, Sugano N, Takoaka K, Ono K. The fate of nontraumatic avascular necrosis of the femoral head: a radiologic classification to formulate prognosis. Clin Orthop 1992;277:73-8.

4. Aaron RK, Lennox D, Bunce GE, Ebert T. The conservative treatment of osteonecrosis of the femoral head: a comparison of core decompression and pulsing electro magnetic fields. Clin Orthop 1989;249:209-18.

5. Mont MA, Hungerford DS. Non-traumatic avascular necrosis of the femoral head. J Bone Joint Surg [Am] 1995;77-A:459-74.

6. Agarwala S, Sule A, Pai BU, Joshi VR. Study of alendronate in avascular necrosis of bone. J Assoc Physicians India 2001;49:949-50.

7. Agarwala S, Jain D, Joshi VR, Sule A. Efficacy of alendronate, a bisphosphonate, in the treatment of AVN of the hip: a prospective open-label study. Rheumatology (Oxford) 2005;44:352-9

8. Agarwala S, Sule A, Pai BU, Joshi VR. Alendronate in the treatment of avascular necrosis of the hip. Rheumatology (Oxford) 2002;41:346-7.

9. Lai KA, Shen WJ, Yang CY, et al. The use of alendronate to prevent early collapse of femoral head in patients with non traumatic osteonecrosis: a randomized clinical study. J Bone Joint Surg [Am] 2005;87-A:2155-9.

10. Nishii T, Sugano N, Miki H, Hashimoto J, Yoshikawa H. Does alendronate prevent collapse in osteonecrosis of the femoral head? Clin Orthop 2006;443:273-9.

11. Mazieres B. Osteonecrosis. In: Hochberg MC, Silman AJ, Smolen JS, Wienblatt ME, Weisman $\mathrm{MH}$, eds. Rheumatology. Fourth ed. Philadelphia: Mosby Elsevier, 2008:1777-89.

12. Ficat RP, Arlet J. Necrosis of the femoral head. In: Hungerford DS, ed. Ischemia and necrosis of bone. Baltimore: Williams and Wilkins, 1980.

13. Ramachandran M, Ward K, Brown RR, et al. Intravenous bisphosphonate therapy for traumatic osteonecrosis of the femoral head in adolescents. J Bone Joint Surg [Am] 2007;89-A:1727-34.

14. Reid IR. Bisphosphonates: new indications and methods of administration. Curr Opin Rheumatol 2003;15:458-63.

15. Davis JC, Huang F, Maksymowych W. New therapies for ankylosing spondylitis: etanercept, thalidomide, pamidronate. Rheum Dis Clin North Am 2003;29:481-94.

16. Calder JD, Buttery L, Revell PA, Pearse M, Polak JM. Apoptosis: a significant cause of bone cell death in osteonecrosis of the femoral head. J Bone Joint Surg [Br] 2004;86-B:1209-13.

17. Sato M, Sugano N, Ohzono K, et al. Apoptosis and expression of stress protein (ORP150, H01) during development of ischaemic osteonecrosis in the rat. $J$ Bone Joint Surg [Br] 2001;83-B:751-9.

18. Omi H, Kusumi T, Kijima H, Toh S. Locally administered low-dose alendronate increases bone mineral density during distraction osteogenesis in a rabbit model. $J$ Bone Joint Surg [Br] 2007;89-B:984-8.

19. Patterson RJ, Bichel WH, Dahlin DC. Idiopathic necrosis of the head of femur. J Bone Joint Surg [Am] 1964;46-A:267-82.

20. Romer U, Wettstein P. Results of treatment of 81 patients with INFH. In: Zinn WM, ed. Idiopathic ischemic necrosis of the femoral head in adults. Stuttgart: Georg Thieme Publishers, 1971:205-12.

21. Zizic TM, Hungerford DS. Avascular necrosis of bone. In: Kelly WN, Harris ED, Ruddy S, et al, eds. Textbook of rheumatology. Philadelphia: W. B. Saunders, 1985:1689-710.

22. Aaron RK, Gray RL. Osteonecrosis: etiology, natural history, pathophysiology, and diagnosis. In: Callaghan JJ, Rosenberg AG, Rubash HE, eds. The adult hip. Baltimore: Lippincot, Williams \& Wilkins, 2007:463-76.
23. Bradway J, Morrey B. The natural history of silent hip in bilateral atraumatic osteonecrosis. J Arthroplasty 1993;8:383-7.

24. Stulberg BN, Davis AW, Bauer TW, et al. Osteonecrosis of the femoral head: a prospective randomized treatment protocol. Clin Orthop 1991;268:140-51.

25. Steinberg ME, Hayken GD, Steinberg DR. The conservative management of avascular necrosis of the femoral head. In: Arlet J, Ficat P, Hungerford D, eds. Bone circulation. Baltimore: Williams \& Wilkins, 1984:398-403.

26. Hungerford DS, Zizic TM. The treatment of ischemic necrosis of the bone in systemic lupus erythematosus. Medicine 1980;59:143-8.

27. Ohzono K, Sugano N, Takaoka K, et al. Natural history of nontraumatic avascular necrosis of the femoral head. J Bone Joint Surg [Br] 1991;73-B:68-72.

28. Musso ES, Mitchell SN, Schink-Ascani M, Bassett CA. Results of conservative management of osteonecrosis of the femoral head: a retrospective review. Clin Orthop 1986;207:209-15

29. Ito H, Matsuno T, Omizu N, Aoki Y, Minami A. Mid-term prognosis of non-traumatic osteonecrosis of the femoral head. J Bone Joint Surg [Br] 2003;85-B:796-801.

30. Hernigou PH, Habibi A, Bachir D, Galacteros F. The natural history of asymptomatic osteonecrosis of the femoral head in adults with sickle cell disease. J Bone Joint Surg [Am] 2006;88-A:2565-72.

31. Nam KW, Kim YL, Yoo JT, et al. Fate of untreated asymptomatic osteonecrosis of the femoral head. J Bone Joint Surg [Am] 2008;90-A:477-84.

32. Min BW, Song KS, Cho CH, Lee SM, Lee KJ. Untreated asymptomatic hips in patients with osteonecrosis of the femoral head. Clin Orthop 2008;466:1087-92.

33. Beaulé PE, Amstutz HC. Management of Ficat stage III and IV osteonecrosis of the hip. J Am Acad Orthop Surg 2004;12:96-105.

34. Babis GC, Soucacos PN. Effectiveness of total hip arthroplasty in the management of hip osteonecrosis. Orthop Clin North Am 2004;35:359-64.

35. Springfield DS, Enneking WJ. Surgery for aseptic necrosis of the femoral head. Clin Orthop 1978;130:175-85.

36. Kenzora JE, Glimcher MJ. Osteonecrosis. In: Kelly WN, Harris ED, Ruddy S, Sledge CB, eds. Textbook of rheumatology. Philadelphia: W.B. Saunders, 1981:1755.

37. Marker DR, Seyler TM, McGrath MS, et al. Treatment of early stage osteonecrosis of the femoral head. J Bone Joint Surg [Am]2008;90-A(Suppl 4):175-87.

38. McGrory BJ, York SC, lorio R, et al. Current practices of AAHKS members in the treatment of adult osteonecrosis of the femoral head. J Bone Joint Surg [Am] 2007;89-A:1194-204.

39. Calder JD, Hine AL, Pearse MF, Revell PA. The relationship between osteonecrosis of the proximal femur identified by MRI and lesions proven by histological examination. J Bone Joint Surg [Br]2008;90-B:154-8.

40. Beaulé PE, Schmalzried TP, Campbell P, Dorey F, Amstutz HC. Duration of symptoms and outcome of hemiresurfacing for hip osteonecrosis. Clin Orthop 2001;385:104-7.

41. Nelson CL, Walz BH, Gruenwald JM. Resurfacing of only the femoral head for osteonecrosis: long-term follow-up study. J Arthroplasty 1997;12:736-40.

42. Little CP, Ruiz AL, Harding IJ, et al. Osteonecrosis in retrieved femoral heads after failed resurfacing arthroplasty of the hip. J Bone Joint Surg [Br] 2005;87-B:320-3.

43. Steinberg DR, Steinberg ME, Garino JP, Dalinka M, Udupa JK. Determining lesion size in osteonecrosis of the femoral head. J Bone Joint Surg [Am] 2006;88A(Suppl 3):27-34

44. Mont MA, Marulanda GA, Jones LC, et al. Systematic analysis of classification systems for osteonecrosis of the femoral head. J Bone Joint Surg [Am] 2006;88 A(Suppl 3):16-26. 